\title{
PATH ANALYSIS FAKTOR YANG MEMENGARUHI KETEPATAN PEMAKAIAN KONTRASEPSI SUNTIK DMPA BERDASARKAN REASONED ACTION THEORY (RAT)
}

\section{PATH ANALYSIS FACTORS AFFECTING THE ACCURACY OF THE USE OF DMPA INJECTION CONTRACEPTION BASED ON REASONED ACTION THEORY (RAT)}

\author{
Eniyati $^{1 *}$, Dechoni Rahmawati ${ }^{2}$, Lily Yulaikhah ${ }^{3}$ \\ ${ }^{*}{ }^{1}$ Unjani Yogyakarta, Jl. Brawijaya Ringroad Barat Ambarketawang Gamping Sleman Yogyakarta, email: \\ eniyati46@yahoo.com, Indonesia \\ ${ }^{2}$ Unjani Yogyakarta, Jl. Brawijaya Ringroad Barat Ambarketawang Gamping Sleman Yogyakarta, email: \\ dechoni.aris@gmail.com, Indonesia \\ ${ }^{3}$ Unjani Yogyakarta, Jl. Brawijaya Ringroad Barat Ambarketawang Gamping Sleman Yogyakarta, email: \\ athasafaraz@gmail.com, Indonesia
}

\begin{abstract}
Background: In Indonesia birth control by injection is the main choice for family planning acceptors (BKKBN, 2015). The highest percentage of new family planning participants in Central Java in 2016 was injection contraception of $5.4 \%$ (Health Profile of Central Java Province, 2016). Active KB participants in Magelang Regency in 2015 used the most non-long-term contraception method type injections, by $50.5 \%$. (Magelang District Health Profile, 2015).

Objective:Analyzing factors that influence the accuracy of DMPA injection KB acceptors based on reasoned action theory in PMB Dhiaulhaq Magelang Regency, with variable attitudes, subjective norm, intentions and behavior.

Methods:Analytic survey research using a cross sectional approach. The population were all DMPA injection KB acceptors, sampling technique uses a case group and a control group that is fixied diseases sampling.

Results:Perception directly affects the norm with a $p$ value of 0.007 . Norm directly affects attitude with a $p$ value of 0.007 . Attitude directly influences intention with a $p$ value of $<0.001$. Intention directly affects the accuracy / usage with a $p$ value of 0.012 .

Conclusion:The intention directly influences the behavior of the accuracy of visits in the use of DMPA injection KB. Perception of control has an indirect effect through subjectifve norms, attitudes, and intentions.
\end{abstract}

Keywords:Appropriate Usage, Contraception, DMPA injection

\section{PENDAHULUAN}

Peningkatan jumlah penduduk merupakan salah satu permasalahan global yang muncul di seluruh dunia di samping isu global warming, keterpurukan ekonomi, masalah pangan, serta menurunnya tingkat kesehatan penduduk. Jumlah penduduk yang besar tanpa disertai kualitas yang memadai akan menjadi beban pembangunan dan menyulitkan pemerintah dalam meningkatkan pertumbuhan ekonomi dan pembangunan nasional. ${ }^{1}$
Pemerintah berupaya untuk menekan laju pertumbuhan penduduk dengan program Keluarga Berencana (KB). Keluarga Berencana (KB) merupakan suatu upaya yang berguna untuk perencanaan jumlah keluarga dengan pembatasan yang dilakukan dengan penggunaan alat-alat kontrasepsi atau penanggulangan kelahiran seperti kondom, Intra Uterine Device (IUD), dan sebagainya. $^{1}$

Cakupan peserta KB baru di Indonesia pada tahun 2015, sebanyak 1.032.054 meliputi suntik sebanyak 546.215 (52.93\%), 
pil KB sebanyak 252.091 (24.43\%), kondom sebanyak 55.737 (5.40\%), implant sebanyak 90.576 (8.87\%), Intra Uterine Device (IUD) sebanyak 71.936 (6.97\%), Metode Operasi Wanita (MOW) sebanyak 14.590 (1.41\%), Metode Operasi Pria (MOP) sebanyak 909 $(0.09 \%)$. Di Indonesia KB suntik menjadi pilihan utama para akseptor KB. ${ }^{1}$

Kontrasepsi suntik adalah cara untuk mencegah terjadinya kehamilan dengan melalui suntikan hormonal. Kontrasepsi hormonal jenis suntik semakin banyak dipakai karena cara kerjanya yang efektif, pemakaiannya praktis, harganya relatif murah, dan aman. $^{2}$

Wanita harus mempertimbangkan dalam pemilihan alat kontrasepsi, wanita harus menimbang berbagai faktor termasuk status kesehatannya, efek samping, konsekuensi terhadap kehamilan, besarnya keluarga yang diinginkan, kerjasama pasangan, dan norma budaya. Pertimbangan yang matang akan memengaruhi keberhasilan menjadi akseptor KB. Ketidaktepatan pada kunjungan ulang akseptor KB suntik sangat berpengaruh terhadap keberhasilan.

\section{BAHAN DAN CARA PENELITIAN}

Penelitian ini merupakan penelitian survey analitik dengan menggunakan pendekatan cross sectional. Penelitian ini menggunakan variabel sikap, norma subjektif, niat dan perilaku diteliti secara bersamaan dalam satu waktu.
Penelitian ini sudah dilakukan di PMB Dhiaulhaq Kabupaten Magelang dengan melibatkan 100 responden. Teknik pengambilan sampel dalam penelitian ini menggunakan kelompok kasus dan kelompok control adalah fixed Diseases Sampling yaitu merupakan skema pencuplikan berdasarkan status penyakit subjek, yaitu berpenyakit atau tidak berpenyakit yang diteliti, sedang status paparan subjek bervariasi mengikuti status penyakit subjek. $^{3}$ Pengambilan data dilakukan dengan menggunakan kuesioner. Data analisis secara univariat menggunakan statistic deskriptif, bivariat menggunakan Uji Chi Square, dan multivariat menggunakan analisis jalur.

\section{HASIL DAN PEMBAHASAN}

Tabel 1. Karakteristik Renponden Berdasarkan Umur dan Pekerjaan $(n=100)$

\begin{tabular}{lcc}
\hline $\begin{array}{l}\text { Karakteristik } \\
\text { Responden }\end{array}$ & Frekuensi & $\begin{array}{c}\text { Persentase } \\
(\mathbf{\%})\end{array}$ \\
\hline Umur & & \\
\hline $21-30$ tahun & 29 & 29 \\
$31-40$ tahun & 54 & 54 \\
41-50 tahun & 17 & 17 \\
\hline Jumlah & 100 & 100 \\
\hline Pekerjaan & & \\
\hline Bekerja & 19 & 19 \\
$\quad$ Tidak bekerja & 81 & 81 \\
\hline Jumlah & 100 & 100 \\
\hline Sumber: Data Primer 2019.
\end{tabular}

Hasil penelitian terkait dengan karakteristik responden dapat dilihat pada tabel diatas.Berdasarkan tabel 1 diketahui bahwa sebagian besar responden berusia 31-40 tahun, yaitu sebanyak 54 responden (54\%), sedangkan status pekerjaan sebagian 
besar responden adalah tidak bekerja, yaitu sebanyak 81 reponden (81\%).

Berdasarkan tabel 2 di bawah diketahui bahwa akseptor dengan niat lemah berjumlah 68 (68 \%) dan yang dengan niat kuat berjumlah 32 (32\%).Norma subjektif dengan tidak mendukung berjumlah 38 (38\%) dan mendukung berjumlah 62 (62\%). Sikap akseptor yang beranggapan negative berjumlah 51 (51\%) dan positif berjumlah 49(49\%). Persepsi control lemah berjumlah 59(59\%) dan kuat berjumlah 41 (41\%). Dan responden tepat pemakaian/kunjungan sebanyak $50(50 \%)$ dan tidak tepat sebanyak 50 (50\%).

Tabel 2. Pengujian Hipotesis Univariat $(n=100)$

\begin{tabular}{lcc}
\hline Variabel & Frekuensi & $\begin{array}{c}\text { Persentase } \\
(\%)\end{array}$ \\
\hline Niat & & \\
\hline Lemah & 68 & 68 \\
$\quad$ Kuat & 32 & 32 \\
\hline Norma Subjektif & & \\
\hline$\quad$ Tidak & 38 & 38 \\
mendukung & & \\
$\quad$ Mendukung & 62 & 62 \\
\hline Sikap & & \\
$\quad$ Negatif & 51 & 51 \\
$\quad$ Positif & 49 & 49 \\
\hline Persepsi Kontrol & & \\
\hline Lemah & 59 & 59 \\
$\quad$ Kuat & 41 & 41 \\
\hline Ketepatan & & \\
Pemakaian & & \\
\hline$\quad$ Tepat & 50 & 50 \\
$\quad$ Tidak tepat & 50 & 50 \\
\hline Suber: Data Pimer 2019. &
\end{tabular}

Sumber: Data Primer 2019.

Berdasarkan Tabel 3 dibawah ini dapat diketahui bahwa ada pengaruh secara langsung antara niat terhadap ketepatan pemakaian atau kunjungan KB suntik DMPA dengan nilai $p$ adalah 0.010 dengan OR 3.14.

Tidak ada pengaruh norma subjektif terhadap ketepatan pemakaian atau kunjungan KB suntik DMPA dengan nilai p 0.680 dengan OR 1.19. Ada pengaruh secara langsung antara sikap terhadap ketepatan pemakaian atau kunjungan KB suntik DMPA dengan nilai p adalah 0.028 dengan OR 2.45 yang berarti ada pengaruh secara langsung antara persepsi control terhadap ketepatan pemakaian atau kunjungan KB suntik DMPA dengan nilai $p$ adalah 0.067 dengan OR 2.13.Berdasarkan nilai OR pada tabel dapat disimpulkan bahwa yang berpengaruh paling tinggi adalah niat, yaitu dengan OR 3.14.

Tabel 3. Pengujian Hipotesis Bivariat $(n=100)$

\begin{tabular}{llllll}
\hline $\begin{array}{l}\text { Independent } \\
\text { Variabel }\end{array}$ & Tepat & $\begin{array}{l}\text { Tidak } \\
\text { tepat }\end{array}$ & Total & OR & $\mathrm{P}^{*}$ \\
\hline $\begin{array}{l}\text { Niat } \\
\text { Kuat }<16\end{array}$ & 28 & 40 & 68 & 3.14 & 0.010 \\
$\begin{array}{l}\text { Lemah } \geq 16 \\
\text { Total }\end{array}$ & 22 & 10 & 32 & & \\
\hline $\begin{array}{l}\text { Norma } \\
\text { Subjektif }\end{array}$ & 50 & 50 & 100 & & \\
$\begin{array}{l}\text { Tidak } \\
\text { mendukung }\end{array}$ & 18 & 20 & 38 & 1.19 & 0.680 \\
$<18$ & & & & & \\
$\begin{array}{l}\text { Mendukung } \\
\geq 18\end{array}$ & 32 & 30 & 62 & & \\
Total & 50 & 50 & 100 & & \\
\hline $\begin{array}{l}\text { Sikap } \\
\text { Negatif }<22\end{array}$ & 20 & 31 & 51 & 2.45 & 0.028 \\
$\begin{array}{l}\text { Positif } \geq 22 \\
\text { Total }\end{array}$ & 30 & 19 & 49 & & \\
\hline $\begin{array}{l}\text { Persepsi } \\
\text { Kontrol }\end{array}$ & 50 & 50 & 100 & & \\
Lemah $<31$ & 25 & 34 & 59 & 2.13 & 0.067 \\
Kuat $\geq 31$ & 25 & 16 & 41 & & \\
Total & 50 & 50 & 100 & & \\
\hline Sumber: Data Primer 2019. & & & \\
\hline
\end{tabular}

Sumber: Data Primer 2019.

Dalam gambar 1 di bawah ini dapat kita lihat bahwa ada pengaruh secara langsung antara niat terhadap ketepatan dalam pemakaian kontrasepsi DMPA. Ada pengaruh secara tidak langsung antara 
persepsi control perilaku terhadap ketepatan pemakaian kontrasepsi DMPA melalui norma subyektif, sikap, dan niat.

Gambar 1. Estimasi Analisis Jalur

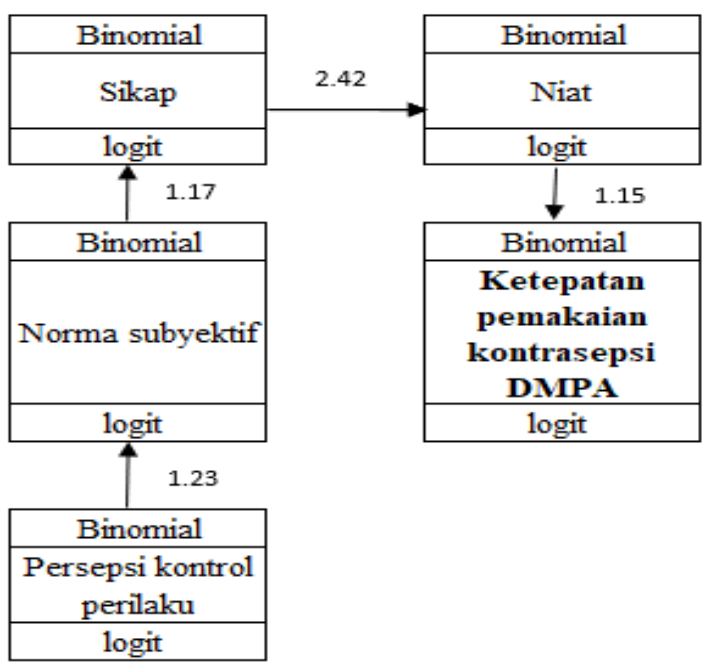

Untuk mengetahui lebih jelas lagi berkaitan dengan pola hubungan dapat dilihat pada tabel 4.

Tabel 4. Hasil Analisis Jalur Ketepatan Pemakaian Kontrasepsi Suntik Di PMB Dhiaulhaq Kabupaten Magelang

\begin{tabular}{|c|c|c|c|c|c|}
\hline \multirow{2}{*}{ Variabel } & \multirow{2}{*}{\multicolumn{2}{|c|}{$\begin{array}{l}\text { Koefisien } \\
\text { Jalur(b) }\end{array}$}} & \multicolumn{2}{|c|}{$\begin{array}{c}\text { Coefisien Interval/ } \\
\mathrm{Cl}(95 \%)\end{array}$} & \multirow{2}{*}{$\mathrm{P}$} \\
\hline & & & Batas & Batas & \\
\hline $\begin{array}{l}\text { Ketepatan } \\
\text { Pemakaian/ } \\
\text { kunjungan }\end{array}$ & Niat & 1.15 & 0.26 & 2.04 & 0.012 \\
\hline $\begin{array}{l}\text { Tidak } \\
\text { langsung } \\
\text { Niat }\end{array}$ & Sikap & 2.42 & 1.34 & 3.51 & $\begin{array}{l}< \\
0.001\end{array}$ \\
\hline $\begin{array}{l}\text { Tidak } \\
\text { langsung } \\
\text { Sikap }\end{array}$ & $\begin{array}{l}\text { Norma } \\
\text { Sub } \\
\text { jektif }\end{array}$ & 1.17 & 0.31 & 2.02 & 0.007 \\
\hline $\begin{array}{l}\text { Tidak } \\
\text { langsung } \\
\text { Norma } \\
\text { Subjektif }\end{array}$ & $\begin{array}{l}\text { Per } \\
\text { sepsi } \\
\text { Kon } \\
\text { trol }\end{array}$ & 1.23 & 0.34 & 2.13 & 0.007 \\
\hline
\end{tabular}

Berdasarkan tabel 4 dapat diketahui bahwa persepsi berpengaruh langsung terhadap norma dengan nilai $p$ sebesar 0.007. Norma berpengaruh langsung terhadap sikap dengan nilai p sebesar 0.007 . Sikap berpengaruh langsung terhadap niat dengan nilai $p$ sebesar $<0.001$. Niat berpengaruh langsung terhadap ketepatan/pemakaian dengan nilai $p$ sebesar 0.012 .

Analisis nilai koefisien jalur niat terhadap ketepatan kunjungan pada pemakaian suntik KB DMPA sebesar 1.15 dengan $p=0.012$. Pengujian ini secara statistik membuktikan bahwa niat berpengaruh signifikan terhadap ketepatan kunjungan pemakaian $\mathrm{KB}$ suntik DMPA.

Niat untuk berperilaku dalam Theory of Behavior atau Teori Perilaku Berencana (TPB) merupakan bentuk kesiapan dari individu untuk melakukan perilaku tertentu. Perilaku manusia dalam TPB dipandu oleh tiga macam pertimbangan, yaitu keyakinan perilaku, keyakinan normative, dan keyakinan control. ${ }^{4}$

Penggunaan DMPA injeksi sebagai kontrasepsi pada periode postpartum merupakan bentuk metode alternatif yang aman dan efektif tanpa efek buruk pada pemberian ASI dan pertumbuhan bayi, sehingga banyak ibu yang berniat untuk memakai DMPA. ${ }^{5}$ Penelitian lain mengatakan bahwa ada hubungan antara lama penggunaan DMPA dengan kejadian obesitas pada peserta KB, sehingga juga memengaruhi niat akseptor KB untuk senantiasa rutin memeriksakan diri atau kontrol rutin agar dapat diketahui secara dini adanya setiap perubahan dalam tubuhnya. ${ }^{6}$ 
Perubahan sikap menurut Hovlan menyebutkan bahwa adanya stimulus dari luar/lingkungan akan menyebabkan seseorang melakukan beberapa proses filter. Sikap positif atau negative tentang suatu perilaku sangat dipengaruhi oleh keyakinan perilaku (behavioral belief) dan penilaian atau ekspektasi tentang hasil dari perilaku. Keyakinan untuk berperilaku ini merujuk pada keyakinan individu berkaitan dengan seberapa besar kemungkinan perilaku yang akan diambil mempunyai implikasi apabila dilakukan. $^{7}$

Hasil analisis jalur menunjukkan ada pengaruh norma subyektif terhadap ketepatan pemakaian atau kunjungan KB suntik DMPA melalui sikap dan niat. Norma subyektif merupakan nilai, aturan, persepsi atau pandangan individu terhadap berbagai macam kepercayaan orang lain yang akanmemengaruhi niatnya untuk melakukan atau tidak melakukan perilaku tertentu dengan berbagai pertimbangan.Hubungan positif antara norma subjektif terhadap ketepatan pemakaian atau kunjungan KB suntik DMPA mempunyai arti bahwa apabila ibu memiliki norma subjektif yang semakin mendukung, maka semakin tinggi niat untuk melakukan kunjungan atau ketepatan pemakaian KB suntik DMPA di BPM Dhiaulhaq Kabupaten Magelang.

Hasil analisis jalur menunjukkan ada pengaruh tidak langsung persepsi kontrol terhadap ketepatan pemakaian/kunjungan KB suntik DMPA melalui norma subjektif, sikap, dan niat. Persepsi control perilaku merupakan persepsi seseorang berkaitan dengan mudah atau sulitnya untuk melakukan suatu perilaku.Dalam penelitian ini didapatkan hasil bahwa ketepatan dalam melakukan kunjungan bagi peserta KB suntik DMPA sangat dipengaruhi oleh faktor internal maupun factor eksternal.Pada factor internal dapat berupa pengetahuan ibu mengenai keuntungan dan kerugian dalam memakai DMPA sedangkan pada faktor eksternal dapat berupa persetujuan ataupun persetujuan dari keluarga yaitu suami.

\section{KESIMPULAN}

Niat berpengaruh langsung terhadap ketepatan /pemakaian dengan nilai $p$ sebesar 0.012. Sikap berpengaruh langsung terhadap niat dengan nilai $p$ sebesar $<0.001$. Norma berpengaruh langsung terhadap sikap dengan nilai $p$ sebesar 0.007 . Persepsi berpengaruh langsung terhadap norma dengan nilai $p$ sebesar 0.007 . Terdapat pengaruh langsung niat terhadap ketepatan /pemakaian KB suntik DMPA.Akseptor KB suntik DMPA sebaiknya melakukan kunjungan sesuai dengan jadwal.

\section{TERIMA KASIH}

1. Kuswanto Hadjo, dr., M. Kes, Dekan Fakultas Kesehatan Jenderal Achmad Yani Yogyakarta, 0274 4342000, email: info@stikesayaniyk.ac.id

2. Deby Rahadian S, M.MR, Ketua PPPM Fakultas Kesehatan Universitas Jenderal 
Achmad Yani Yogyakarta, 02744342000 ,

email: pppm@stikesayaniyk.ac.id

\section{KEPUSTAKAAN}

1. BKKBN. Laporan BKKBN Tahun 2013.

2. BKKBN. Hasil Pelayanan Peserta KB Baru Secara Nasional. 2015.

3. Murti, B. Desain dan Ukuran Sampel Untuk Penelitian Kuantitatif dan Kualitatif Di Bidang Kesehatan. 2013.

4. Aizen. The Teory of Plane Behaviour University of Massachusetts at Amherst. 2005.

5. Singhal S, Sarda N, Gupta S, and G. S. Impact of Injectable ProgestogenContraception in Early Puerperium on Lactation and Infant Health. J Clin Diagn Res, 2014. 8(3), 6972.

6. Suciana, Rajudin, G. A. Hubungan lama PenggunaanKontrasepsi Depo Medroxi Progesteron Asetat (DMPA) dengan Obesitas. 2013. Jurnal Unimal Malang.

7. Murti, B. Teori Promosi dan Perilaku Kesehatan.2018. Edisi ke-1. 